\title{
Sorption of Gadolinium (III) Ions by a Natural Clinoptilolite-Containing Tuff
}

\author{
Nina M. Kozhevnikova, Ekaterina N. Styazhkina \\ Baikal Institute of Nature Management, Siberian Branch, Russian Academy of Sciences, Ulan-Ude, Russia \\ Email: nicas@binm.bscnet.ru
}

Received July 3, 2013; revised July 31, 2013; accepted August 7, 2013

Copyright (C) 2013 Nina M. Kozhevnikova, Ekaterina N. Styazhkina. This is an open access article distributed under the Creative Commons Attribution License, which permits unrestricted use, distribution, and reproduction in any medium, provided the original work is properly cited.

\begin{abstract}
The equilibrium and kinetics of sorption of gadolinium (III) ions from sulfate solutions by a natural clinoptilolite containing tuff are studied. It is shown that gadolinium is completely extracted from dilute solutions $(<0.002 \mathrm{M})$. The kinetic parameters of the sorption process are determined.
\end{abstract}

Keywords: Natural Zeolite; Gadolinium Ions; Sulfate Solutions; Sorption Isotherms; Kinetic Laws

\section{Introduction}

Natural zeolites are used as sorbents in chemical engineering, hydrometallurgy, industrial ecology, agriculture, and medicine [1]. Natural zeolites modified with ions of rare earth elements (REEs) are promising for the preparation of effective stimulants for regener ative therapy and biologically active agents $[1,2]$. REEs are used in the treatment of tuberculosis, tumors, and skin diseases. Lanthanum sulfate exhibits anticoagulant action. Lanthanum, cerium, praseodymium, gadolinium introduced into the zeolite matrix have a neuroprotective effect [3]. It is considered effective to use calcium blockers for reducing the ischemic brain damage. In biological systems, ions of lanthanum, cerium, praseodymium, gadolinium replace calcium ions, block their entry into cells, and have an inhibitory effect on the development of a calcium induced cascade of pathological reactions in cerebral ischemia [3]. Sorption technology makes it possible to enhance the biological activity of natural zeolites, which play the role of a prolonging carrier of REE ions.

Our insufficient knowledge of the ion exchange properties of natural zeolites with respect to REE ions limits the possibilities of their use. The ion exchange properties of natural zeolites with respect to REE ions are inadequately understood. Earlier, we studied the sorption of lanthanum, cerium, neodymium, and samarium ions by mordenite and clinoptilolite tuff $[1,3]$. There are no data on the sorption of gadolinium ions by natural zeolites, and such data are needed to estimate the effect of the nature of REEs on the equilibrium and kinetics of sorp- tion, which require deeper analysis. We therefore studied the sorption of gadolinium (III) ions from sulfate solutions by a clinoptilolite tuff as function of solution concentration, sorbent grain size, and solid to liquid weight ratio.

\section{Experimental}

\subsection{The Compounds Clinoptilolite Tuff}

In this work, we used clinoptilolite tuff of the Kholinsk deposit with the following content of components (wt\%): $68.11-\mathrm{SiO}_{2}, 12.84-\mathrm{Al}_{2} \mathrm{O}_{3}, 1.08-\mathrm{Fe}_{2} \mathrm{O}_{3}, 0.35-\mathrm{FeO}$, $0.08-\mathrm{Mn}, 0.05-\mathrm{P}_{2} \mathrm{O}_{5}, 0.58-\mathrm{TiO}_{2}, 4.17-\mathrm{CaO}, 2.65-$ $\mathrm{MgO}, 2.47-\mathrm{K}_{2} \mathrm{O}, 2.87-\mathrm{Na}_{2} \mathrm{O}, 0.003-\mathrm{CuO}$, and $0.002-$ $\mathrm{F} ; \mathrm{Si} / \mathrm{Al}=5.25$. The content of the zeolite in the rock of $\sim 60 \%-62 \%$ was determined via $\mathrm{X}$ ray diffraction analysis using a PTsL-2 instrument [4]. Grain fractions with sizes of $0.25-0.5$ and $1-2 \mathrm{~mm}$ were selected for analysis by the sieving method. The sorption equilibrium was studied under static conditions from gadolinium sulfate solutions in the concentration range of the ion to be determined of 0.0003 to $0.025 \mathrm{M}$ at the ratio of solid(s) and liquid (1) phases of 1:10 and 1:0.

\subsection{The Kinetic Parameters}

The kinetic parameters were calculated from $Q-\tau$ curves (where $Q$ is the sorbed amount of gadolinium ions, $\mathrm{mmol} / \mathrm{g} ; \tau$ is the time, s) using the technique described for sorption on zeolites in [5]. For the initial period of time, when sorption occurs on the surface of the sorbent 
and the process is controlled by an outer diffusion mechanism, the rate constant $R$ of the outer diffusion process is calculated through the equation where $\mathrm{c}$ is the concentration of the ion being exchanged in the solution (M), and $K_{d}$ is the equilibrium distribution coefficient $(\mathrm{ml} / \mathrm{g})$ :

$$
\begin{gathered}
R=Q / \mathrm{d} \tau\left(1 / c K_{d}\right) \\
K_{d}=\left(C_{0}-C_{e q}\right) V / C_{e q} m
\end{gathered}
$$

where $c_{0}$ and $c_{e q}$ are the initial and equilibrium con centrations of gadolinium ion in the solution; $V$ is the solution volume, $\mathrm{ml}$; and $\mathrm{m}$ is the weighted portion of the zeolite, $g$.

As the time of contact increases, the number of absorbed ions is determined by the exchange rate within the sorbent grain. The effective diffusion coefficient $(D)$ and the rate constant of the inner diffusion process $(B)$, which characterize the inner diffusion mechanism, were calculated using the equations derived for spherical particles:

$$
\begin{gathered}
F=Q_{\tau} / Q_{\infty}=(6 / r)(1 / 2 D r / \pi) \\
B=\pi 2 D / \pi 2
\end{gathered}
$$

where $F$ is the degree of absorption of gadolinium ions, and $r$ is the average radius of sorbent grains. The content of gadolinium ions was determined by photometry with arsenazo (III) [6]. The absorption capacity was calculated from the difference in the concentrations of gadolinium ions before and after sorption using the results of three parallel experiments.

The experimental results are presented in the Table $\mathbf{1}$ and in Figures 1-3.

\section{Results and Discussion}

The equilibrium curves of gadolinium sorption on the

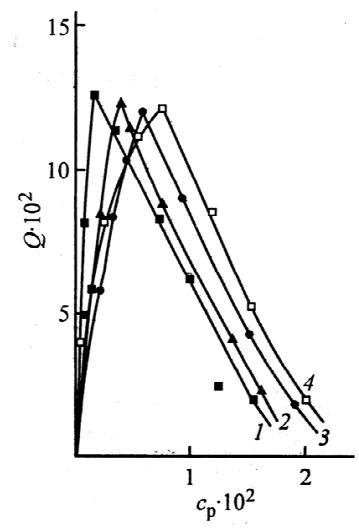

Figure 1. Equilibrium curves of sorption of gadolinium from $\mathrm{Gd}_{2}\left(\mathrm{SO}_{4}\right)_{3}$ solutions $Q$ is the sorbed number of ions, $\mathrm{mmol} / \mathrm{g}$; $\mathrm{c}$ is the equilibrium concentration of the ion exchanged in the solution, mol/l. Grain size: $d=(1,2) 0.25$ 0.5 and $(3,4) 1-2 \mathrm{~mm}$; s:I = $(2,4) 1: 10$ and $(1,3)$ 1:50.

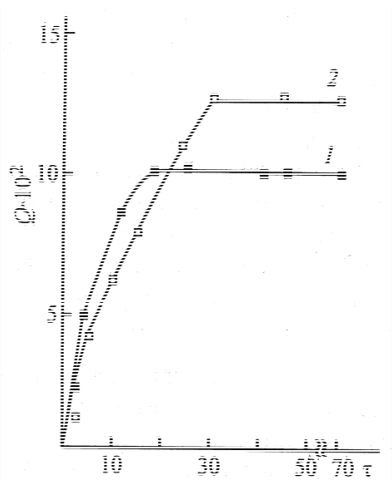

Figure 2. Kinetic curves of the sorption of gadolinium from (1) $0.001 \mathrm{M}(\mathrm{d}=0.25-0.5 \mathrm{~mm}$ and s:l = 1:50) and (2) 0.005 $M\left(d=1-2 \mathrm{~mm}\right.$ and s:l = 1:10) solution of $\mathrm{Gd}_{2}\left(\mathrm{SO}_{4}\right)_{3}$ by the clinoptilolite containing tuff; $Q$ is the sorbed number of ions, $\mathrm{mmol} / \mathrm{g} ; \boldsymbol{\tau}$ is the time, $\mathrm{h}$.

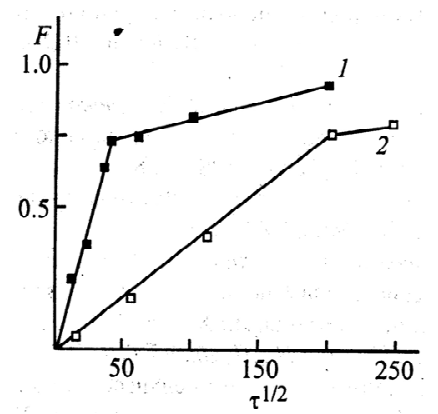

Figure 3. $F-\tau^{1 / 2}$ dependences for the sorption of gadolinium from the $\mathrm{Gd}_{2}\left(\mathrm{SO}_{4}\right)_{3}$ solution: (1) $0.001 \mathrm{M}, \mathrm{d}=0.25-0.5 \mathrm{~mm}$, and $s: I=1: 50$ and (2) $0.005 \mathrm{M}, \mathrm{d}=1-2 \mathrm{~mm}$, and $\mathrm{s}: \mathrm{l}=1: 10$. $F$ is the degree of filling of the zeolite phase (arb. units); $\tau$ is time, $s$.

clinoptilolite containing tuff show the quantitative extraction of gadolinium from dilute solutions (Figure 1). For clinoptilolite grains with sizes of both $1-2 \mathrm{~mm}$ (at $\mathrm{s}: 1=1: 10$ ) and $0.25-0.5 \mathrm{~mm}($ at $\mathrm{s}: 1=1: 50)$, gadolinium ions are more completely extracted in the range of the initial solution concentration of up to $0.002 \mathrm{M}$.

As the solution concentration increases, the equilibrium curves pass through a maximum, which is followed by a decrease in the exchange capacity (EC) of the tuff. The maximum EC is $\sim 0.126-0.138 \mathrm{mmol} / \mathrm{g}$. The occurrence of an extrenum in the isotherm can be attributed to the solution containing intermediate reaction products to which the sorbent exhibits high selectivity [7,8]. Gadolinium has a high tendency to complexation; in neutral and acid aqueous solutions, gadolinium ions are in the form of aqua complexes of the $\left[\mathrm{Gd}\left(\mathrm{H}_{2} \mathrm{O}\right)_{\mathrm{n}}\right]^{3+}$ or $\left[\mathrm{Gd}\left(\mathrm{H}_{2} \mathrm{O}\right) \cdot \mathrm{nOH}\right]^{2+}$ type, where $\mathrm{n}=5-8[9,10]$. The decrease in the sorption of gadolinium after the maximum is apparently caused by the complex specific pattern of inter action between gadolinium ions and the zeolite containing tuff. 
Table 1. Kinetic parameters of the sorption of gadolinium by natural clinoptilolite, containing tuff from $\mathrm{Cd}_{2}\left(\mathrm{SO}_{4}\right)_{3}$ solutions.

\begin{tabular}{ccccccccc}
\hline$c, \mathrm{M}$ & $d, \mathrm{~mm}$ & $\mathrm{~s}: 1$ & $\tau_{\infty}, \mathrm{min}$ & $\begin{array}{c}(\mathrm{d} Q / \mathrm{d} \tau) \times 10^{5}, \\
\mathrm{mmol} /(\mathrm{g} \cdot \mathrm{min})\end{array}$ & $K_{\mathrm{d}}, \mathrm{ml} / \mathrm{g}$ & $R \times 10^{4}, \mathrm{~s}^{-1}$ & $B \times 10^{4}, \mathrm{~s}^{-1}$ & $D^{\prime} \times 10^{8}, \mathrm{~cm}^{2} / \mathrm{s}$ \\
\hline 0.001 & $0.25-0.5$ & $1: 10$ & 1555 & 3.8 & 54.8 & 23.3 & 9.7 & 4.6 \\
0.005 & $0.25-0.5$ & $1: 50$ & 1578 & 3.3 & 47.2 & 21.4 & 10.5 & 5.2 \\
0.005 & $1-2$ & $1: 10$ & 2063 & 1.6 & 28.1 & 11.6 & 6.9 & 3.4 \\
\hline
\end{tabular}

The formation of complexes with the composition $\left[\mathrm{Gd}\left(\mathrm{SO}_{4}\right)_{\mathrm{n}}\right]^{3-2 \mathrm{n}}$, where $n=1-3$, was also observed in gadolinium ${ }^{n}$ sulfate solutions. At low concentrations of sulfate ions $(<0.02 \mathrm{~mol} / \mathrm{l}),\left[\mathrm{GdSO}_{4}\right]^{+}$cations dominate [9], although anionic complexes can also be formed under these conditions [10-12]. The sorption of aqua and hydroxo complexes of gadolinium apparently takes place before the extremum point, since the high selectivity of zeolite to gadolinium ions in the initial portion of the equilibrium curve, when the ions are nearly completely absorbed, is due to the high charge of the ion. The mechanism of sorption of lanthanum aqua complexes on a synthetic zeolite is described in [12]; the assumed mechanism is evidenced by the reversal of the selectivity of the sorbent to gadolinium ions after their certain concentration in the solution is achieved. This can be attributed to the manifestation of electroselectivity, because (according to theory $[7,8,10]$ ) the equilibrium in the solution-sorbent system shifts in the direction of an increase in the sorption of an ion with a higher charge upon the dilution of the solution; when it is concentrated, a complete reversal of selectivity is observed.

The absorption of gadolinium ions is accompanied by a decline in the solution $\mathrm{pH}$ by $0.6-0.9$ units. The $\mathrm{pH}$ value is 6.3 for a $0.005 \mathrm{M}$ gadolinium sulfate solution and 6.1 for $0.001 \mathrm{M}$. The grain size and the solid to liquid weight ratio affect the position of the maximum in the isotherms (Figure 1). The maximum of EC on grains with $d=0.25-0.5 \mathrm{~mm}$ and $\mathrm{s}: 1=1: 50$ (Figure 1, curve 1) is shifted to the range of lower equilibrium concentrations; with an increase in the grain size $(\mathrm{d}=1-2 \mathrm{~mm})$ at $\mathrm{s}: 1=1: 10$, the maximum is the range of higher concentrations (Figure 1, curve 4). Low solution concentrations are thus sufficient for achieving a maximum EC on fine grains; this is important in choosing the mode for saturating the zeolite with gadolinium ions to prepare a modified form of the clinoptilolite containing tuff.

It was found that a nearly equilibrium state is achieved within $28 \mathrm{~h}$ on grains with a size of $0.25-0.5 \mathrm{~mm}$ and within $35 \mathrm{~h}$ on grains with a size of $1-2 \mathrm{~mm}$; after that, a slight desorption within 1.5\% - 2.0\% is observed (Figure 2). An analysis of the kinetic parameters (Table 1) shows that the sorption of gadolinium is controlled by a mixed diffusion mechanism, since the rate constants of outer $(R)$ and inner diffusion processes $(B)$ are on approximately the same order of magnitude. The behavior of the dependence of the degree of filling of the zeolite phase $F$ on $\tau^{1 / 2}$ (where $\tau$ is the time in seconds), the initial portions of which are linear up to high values of $\mathrm{F}$ (Figure 3), is indicative of a considerable contribution from the inner diffusion mechanism.

An increase in the rate of sorption of gadolinium $\mathrm{d} Q / \mathrm{d} \tau$ from a dilute solution on grains with a size of $0.25-0.5 \mathrm{~mm}$ by the outer diffusion mechanism and an increase in the equilibrium distribution coefficient $K$ are observed. The acceleration of the process is attributed to an increase in the degree of dispersion of the tuff grains. The values of the effective diffusion coefficient $D$ are in agreement with those from [5]. The relatively high values of $D$, relative to those derived for mono and divalent metals, are explained by the Helfferich principle [12], according to which more mobile ions decelerate and less mobile ions accelerate during the exchange of a mixture of ions.

\section{Conclusion}

When natural zeolite tuff comes into contact with aqueous sulfate solutions of gadolinium, the sorbent has the property of extracting gadolinium ions. At low concentrations $(<0.002 \mathrm{M})$, a high selectivity of sorption of gadolinium ions is observed; as the concentration increases, the sorption capacity of the clinoptilolite containing tuff decreases. The sorption isotherms exhibit a maximum attributed to a complex pattern of interaction in the sorbent-solution system. The kinetics of sorption of gadolinium (III) ions by natural clinoptilolite containing tuff is controlled by a mixed diffusion sorption mechanism; it is found that the contribution of the inner diffusion sorption mechanism is substantial. It is established that the rate of absorption of gadolinium ions from a dilute solution on grains with sizes of $0.25-0.5 \mathrm{~mm}$ by the outer diffusion mechanism and the equilibrium distribution coefficient increase with decreasing solution concentration.

\section{Acknowledgements}

This work was carried out with the financial support of 
the Russian Foundation for Basic Research, grant number 12-05-00020a.

\section{REFERENCES}

[1] T. E. Aleksandrova, V. S. Maksarov, V. S. Ubasheev and N. M. Kozhevnikova, "Experimental Evaluation of Pharmaceutics Properties of Lanthanum Sulfate," Siberian Medical Zhurnal, No. 4, 2001, p. 65.

[2] O. A. Verkhova and V. R. Soroka, "The Biological Role of the Lanthanide," Biology Bulletin Reviews, No. 3, 1980, p. 365 .

[3] S. M. Gulyaev, I. O. Ubasheev and N. M. Kozhevnikova, "Neuroprotective Effect of Lanthanum Acetate in Patients with Chronic Cerebral Ischemia in Rats," Vestnik Buryat State University, Ulan-Ude, No. 2, 2007, p. 86.

[4] I. A. Belitskii, I. V. Drobot and G. P. Valueva, "Experi ence in Rapid Determination of Zeolite Content in Rock, Using PTsL 1 and PTsL 2 Portable Zeolite Laboratories," Nauka, Novosibirsk, 1979, p. 80.

[5] Yu. A. Kokotov, P. P. Zolotarev and G. E. El'kin, "The oretic Bases of Ion Exchange,” Khimiya, Leningrad, 1986, p. 280 .

[6] N. N. Tunitskii, V. A. Kaminskii and S. F. Timashev, "Methods of Physicochemical Kinetics" Khimiya, Moscow City, 1972, p. 246.

[7] P. Geoffrey, "Chemical Methods of Rock Analysis," Mir, Moscow City, 1973, p. 360.

[8] N. F. Chelishchev, V. F. Volodin and V. L. Kryukov, "Ion Exchange Properties of Natural High Silicon Zeo lites," Nauka, Moscow City, 1988, p. 128.

[9] L. N. Komissarova, V. M. Shatskii, G. Ya. Pushkina, et al., "Compounds of Rare Earth Elements. Carbonates, Oxalates, Sulfates, Titanates," Nauka, Moscow City, 1986, p. 366.

[10] K. B. Yatsemirskii, N. A. Kostromina, Z. A. Sheka, et al., "Chemistry of Complex Rare Earth Compounds," Naukova Dumka, Kiev, 1966, p. 494.

[11] F. H. Spedding and S. Jappe, "“'Conductances, Solubilities and Ionization Constants of Some Rare-Earth Sulfates in Aqueous Solutions at 25," Journal of the American Chemical Society, Vol. 76, No. 5, 1964, p. 882.

[12] F. Helfferich, "Ion Exchange," Foreign Literature Publishing House, Moscow City, 1962, p. 460. 